\title{
Supplementary material of "Importance of different parameterization changes for the updated dust cycle modelling in the Community Atmosphere Model (version 6.1) \\ פ
}

Longlei Li ${ }^{1}$, Natalie M Mahowald ${ }^{1}$, Jasper $\mathrm{F} \mathrm{Kok}^{2}$, Xiaohong Liư ${ }^{3}$, Mingxuan $\mathrm{Wu}^{4}$, Danny M. Leung ${ }^{2}$, Douglas S Hamilton ${ }^{1}$, Louisa K. Emmons ${ }^{5}$, Yue Huang ${ }^{2,7,8}$, Jun Meng ${ }^{2}$, Neil Sexton ${ }^{1}$, and Jessica Wan ${ }^{6}$

${ }^{1}$ Department of Earth and Atmospheric Sciences, Cornell University, Ithaca, NY, United States ${ }^{2}$ Atmospheric and Oceanic Sciences, University of California, Los Angeles, CA, United States ${ }^{3}$ Department of Atmospheric Sciences, Texas A\&M University, College Station, TX, United States

${ }^{4}$ Atmospheric Sciences and Global Change Division, Pacific Northwest National Laboratory, Richland, WA, United States

${ }^{5}$ Atmospheric Chemistry Observations and Modeling Laboratory, National Center for Atmospheric Research, Boulder, CO, United States

${ }^{6}$ Scripps Institution of Oceanography, University of California San Diego, La Jolla, CA, USA

${ }^{7}$ Earth Institute, Columbia University, New York, NY 10025, USA

${ }^{8}$ NASA Goddard Institute for Space Studies, New York, NY 10025, USA

Correspondence to: Longlei Li (II859@cornell.edu) 


\section{Calculation of the asphericity factor}

We describe here how we calculated the asphericity factor and associated assumptions and present results of the asphericity factor we obtained.

The orientation of particles during the gravitational settling determines the drag coefficient. Horizontally oriented particles have a low terminal settling velocity compared to vertically oriented particles (Mallios et al., 2020). At high Reynolds numbers (e.g., $\operatorname{Re}>1000$ ), particles tend to fall with the maximum projected area perpendicular to the falling direction to maximize the resistance to gravitational settling, as for instance occurs for large ice crystals in cirrus clouds (Platt et al., 1978). However, for dust falling in the Earth's atmosphere, it is reasonable to assume a random orientation (Bagheri and Bonadonna 2016), because 1) Re $<1$ (Kok et al, 2012), and, especially, 2) Community Atmosphere Model (version 6; CAM6) does not simulate super coarse dust particles (diameter $>10 \mu \mathrm{m}$ ), for which such an assumption may introduce high errors. With these assumptions, we follow Huang et al. (2020) in approximating $y$ for the ellipsoidal dust aerosol particles using the treatment in Bagheri and Bonadonna (2016) as

where

$$
\gamma=\frac{2}{F_{s}^{1 / 3}+1 / F_{s}^{1 / 3}}
$$

$$
F_{S}=\frac{D_{g}^{3}}{L^{2.3} \cdot W^{0.7}}
$$

and $D_{g}$ is the volume-equivalent diameter of the dust particle defined by three axes ( $L$ : length, $\mathrm{W}$ : width, and $\mathrm{H}$ : height, respectively) of the ellipsoid having a form of

$$
\mathrm{D}_{\mathrm{g}}=\sqrt[3]{\mathrm{LWH}}
$$

This approximation (Eq. 1) of the influence of the dust asphericity on the gravitational settling velocity has been shown to be accurate and reliable with a mean and the maximum errors of $2.4 \%$, and $33.9 \%$, respectively (Bagheri and Bonadonna 2016). Equations (1) and (3) indicates a range of $\mathrm{y}$ between 0 and 1 . When a dust particle becomes less ellipsoidal $\gamma$ is getting closer to 1.

In the Stokes regime (Kok et al., 2012) where the gravitational settling of dust usually occurs, the terminal velocity of spherical (sph) and ellipsoidal (asp) dust is approximated as

and

$$
\mathrm{V}_{\mathrm{sph}}=\frac{\mathrm{g} \rho_{\mathrm{p}}}{18 \mu} \mathrm{D}_{\mathrm{g}}^{2}
$$

$$
\mathrm{V}_{\text {asp }}=\gamma \mathrm{V}_{\mathrm{sph}} \text {, }
$$


respectively, where $\mathrm{g}$ is the gravitational constant $\left(\sim 9.8 \mathrm{~m} \mathrm{~s}^{-2}\right), \rho_{\mathrm{p}}$ is the dust density $\left(\sim 2,500 \mathrm{~kg} \mathrm{~m}^{-3}\right), \mu$ is the dynamic viscosity of air $\left(1.81 \times 10^{-5} \mathrm{~Pa} \mathrm{~s}\right)$.

Measurements made at different locations show that the shape parameters (e.g., aspect ratio; Fig. 3 of Huang et al., 2020), which we used to calculate $V_{\text {asp }}$, change for dust during transport. Because of highly limited measurements available, following Huang et al. (2020) we simplify the horizontal transport of dust into "close-to-source", "shortrange", and "long-range" zones for dust from each source region according to source apportionments based on the annual mean dust loading following Kok et al. (2021) but from simulations conducted here in default CAM6.1. In the regions where the shape parameter measurement is sparse or unavailable, such as those in the Southern Hemisphere, the shape parameters from the global median are used instead to calculate the asphericity factor. This simplified treatment yields a change comparable to the simulation where we reduced the gravitational settling velocity of dust by $\sim 15 \%$ globally in the modeled dust cycle from simulations without considering the gravitational settling lifetime of the dust asphericity.

In addition, we assume the dust shape parameters are independent of the size of dust aerosol particles. Therefore, a constant revision of the dust gravitational settling velocity (the calculated value in the model by default is for spherical aerosols) due to dust asphericity by multiplying the velocity by $\mathrm{Y}$ was applied to dust species in the three modes that contains dust aerosol (Aitken, accumulation, and coarse). The size independency assumption of dust asphericity follows the recently observational evidence that there does not exist a statistically significant relationship between the shape parameters (aspect ratio and height-to-width ratio) and dust sizes (Huang et al., 2020).

Using Eqs. (1-3) and the shape parameter measurements, we calculated the asphericity factor $y$ for each of the "close-to-source", "short-range", and "long-range" zones. We applied a $15 \%$ constant $y$ for the other regions with no shape parameter measurements. Figure $\mathrm{S} 1$ shows the map of the asphericity factor $\mathrm{y}$ we obtained. Dust originating from East Asia, which is enriched in calcium, might become less aspherical during transport (Huang et al., 2020). The reduction in dust asphericity during transport likely occurs because of chemical reactions with acidic gases at the dust surface forming a uniform soluble coating around the core. This acidic gas could be nitric acid, for example, as dust aerosols travel through the dense urban and industrial areas of the East Asian continent, or hydrochloric acid released from sea salt when dust resides in the remote marine boundary layer (Tobo et al., 2010). Therefore, as shown in Fig. S1, we applied a small "correction" to the calculated gravitational settling velocity in the model for dust from East Asia in the long-range transport zone. In contrast to the reduced asphericity of East Asian dust during transport, dust originating from North Africa tends to increase its asphericity when crossing the North Atlantic Ocean (Huang et al., 2020). Field measurements suggest an aspect ratio of $\sim 1.60$ for dust aerosol particles close to North African sources, and it statistically significantly increases to 1.90 for dust from North Africa and experiencing long-range transport (Huang et al., 2020). This increasing 
aspect ratio of dust during transport likely occurs because spherical dust is more readily settled out owning to the relatively large gravitational settling velocity compared to nonspherical dust (Yang et al., 2013). Therefore, a large fraction of non-spherical dust at regions remote to the source remains. Consistent to the increased asphericity of dust during transport, the dry deposition velocity reduction is greater for dust further away from the North African continent (Fig. S1).

\section{Calculation of the threshold gravimetric water content}

Fécan et al. (1999) parameterized the threshold gravimetric water content $(w)$ of the top soil layer by

$$
w=b\left(17 f_{\text {clay }}+14 f_{\text {clay }}^{2}\right),
$$

where $w$ is in percentage, $b$ is a tuning factor, and $f_{c l a y}$ is the clay fraction. The tuning factor $b$ is set to be $1 / f_{\text {clay }}$ and unity in the default CAM6.1-CLM5 (Community Land Model version 5), and the updated CAM6.a, respectively. The clay fraction is taken from the $\mathrm{FAO}(2012)$ soil database (see Fig. S1 of Kok et al., 2014).

\section{Descriptions of the data used in the model-observation comparison}

\section{Surface dust concentrations and dust aerosol optical depth from AERONET}

We use monthly data from measurements using high-volume filter collectors at the University of Miami Ocean Aerosol Network and station-based data that have been previously compiled on annual averages (Mahowald et al., 2009; Zuidema et al., 2019). Simulated dust optical depth (DOD) is compared to Aerosol Robotic Network

(AERONET) retrievals subject to data quality control and station selection based on the dust dominance in the reported aerosol optical depth (AOD; see Albani et al., 2014 for details).

\section{Surface dust deposition fluxes}

The dust deposition flux data used here were from the Albani et al. (2014) compiled from publications (Tegen et al., 2002; Ginoux et al., 2001; Lawrence and Neff, 2009; Mahowald et al., 2009) for the present-day climate. Because the model only simulates dust $<10 \mu \mathrm{m}$ (the cut off value of aerosol size) in diameter, the Albani et al. (2014) compilation has been processed to estimate the surface concentration of dust below the size cut-off, according to reported or assumed parameters (e.g., geometric standard deviation) for the size distribution of transported dust.

\section{Size distributions of dust aerosol}

Most of the remotely sensed, size-resolved dust volume retrievals used here were taken from the AERONET Level 2.0 Almucantar Retrievals (Version 2), which is reported for 22 size bins with bimodal size distribution and ellipsoid shape of aerosol particles 
(Dubovik et al., 2000). This data is known to overestimate dust mass in the submicron size range and has possible contamination by non-dust aerosols (Albani et al., 2014; Dubovik et al., 2000; Mahowald et al., 2014). We, therefore, only retain the super micron fraction of dust in the comparison, even though AERONET may underestimate the mass of dust between 1-10 $\mu \mathrm{m}$ in diameters (McConnell et al., 2008). The data processing procedure is detailed in Albani et al., (2014). Near North Africa, we also compare the modelled size distribution of dust aerosols with measurements from Otto et al. (2007) taken in the vicinity of the Canary Islands, from Ryder et al. (2013) by aircraft with a track between the Canary Islands and Mauritania/Mali, and from Ryder et al. (2018) near Cape Verde.

\section{Vertical profiles of dust aerosol}

The modeled vertical distribution of dust is evaluated via comparison between the modeled and measured vertical dust extinction profile. The modeled dust extinction at the visible band is compared to the Cloud-Aerosol Lidar with Orthogonal Polarization (CALIOP) retrievals for years of 2007-2009 (Luo et al., 2015b, 2015a) during the nighttime because of their high quality without sunlight interference compared to daytime retrievals. This CALIOP dust extinction dataset performs better in terms of dust separation and detection, even for thin dust aerosol layers, than that of its standard product. Since the modeled aerosol extinction at the visible band in CAM6 by default is for all aerosol species, we modified the code to diagnose the extinction due to dust aerosol only online at every other model time step (one model time step $=30 \mathrm{~min}$ ). Based on the simulated 3-dimensional dust extinction (recorded monthly during the simulation), we then offline derived the 3-dimensional DOD and the centroid height of dust plumes.

A second comparison of vertical distribution is through a centroid height of dust plumes. The centroid height of dust plumes is defined as altitude of the midpoint of the vertical DOD profile and thus reflects the vertical distribution of dust (Kim et al., 2014). We compare the centroid height of the dust plume derived from the modeled dust extinction profile with that derived from Atmospheric Infrared Sounder (AIRS) and CALIOP measurements in three subregions over North Atlantic and North Africa during the nighttime of $2007-2009$. The three subregions include North Africa land: $\left[17^{\circ} \mathrm{W}-30^{\circ} \mathrm{E}\right.$, $\left.0^{\circ}-35^{\circ} \mathrm{N}\right]$; eastern and western North Atlantic: $\left[17^{\circ} \mathrm{W}-50^{\circ} \mathrm{W}, 0^{\circ}-35^{\circ} \mathrm{N}\right]$, and $\left[50^{\circ} \mathrm{W}-30^{\circ} \mathrm{E}\right.$, $0^{\circ}-35^{\circ} \mathrm{N}$ ], respectively, following Kim et al. (2014). We selected these subregions because: 1) almost half of global dust emissions originate from North Africa (see Kok et al., 2021); 2) the long-range westward transport of dust across the North Atlantic has been widely recognized; and 3) the gridded aerosol products of CALIOP are of high regional and seasonal consistency over North Africa and the Atlantic.

\section{Satellite-based regional DOD}

We compare the modeled regional DOD averaged over subdomains as defined in Fig. $3 \mathrm{~b}$ (x-axis labels) of the main text with that derived from MODIS aerosol product (collection 6; level 2) onboard Terra and Aqua as processed by Pu et al. (2020). They separated dust from scattering aerosols by utilizing single scattering albedo, Ångström 
exponent (AE), and an empirical function that relates $D O D$ to $A O D$ and $A E$. See Pu et al. (2020) for details.

\section{The direct radiative effect efficiency of dust}

The modeled direct dust direct radiative effect (DRE) efficiency (ratio of clear-sky dust DRE to all-sky DOD) is compared to satellite- and/or model-based results under clearsky conditions at the top of the atmosphere. See detailed descriptions in Table 3 and the references therein.

\section{Other datasets}

In addition to the abovementioned observations, we compare our results to datasets which combine model simulations and observations. Specifically, we compare 1) modeled transported dust size distribution with that from the Dust Constraints from joint Observational-Modelling-experiMental analysis (DustCOMM) (Adebiyi et al., 2020) in global average; 2 ) regional dust deposition fluxes with the semi-observational data that were inverted based on an integration of a global model ensemble and qualitycontrolled observational constrains on the transported dust size distribution, extinction efficiency, and regional DOD (Kok et al., 2021). This set of semi-observational data was shown to compare better with the high-quality measurement than model ensemble means or any individual model (Kok et al., 2021); and 3) regional DOD seasonally with the estimates of Ridley et al. (2016), who obtained DOD by combining four global climate models with multiple satellite aerosol products that were bias corrected using station-based AEROENT data. 


\section{Supplementary figures}

Figure $\mathbf{S 1}$. Gravitational settling velocity ratio of spherical $\left(\mathrm{V}_{\text {asp }}\right)$ to ellipsoidal $\left(V_{\text {sph }}\right)$ dust. Shape parameters for each major source (defined based on source apportionment) are taken from the global median of Huang et al., (2020).

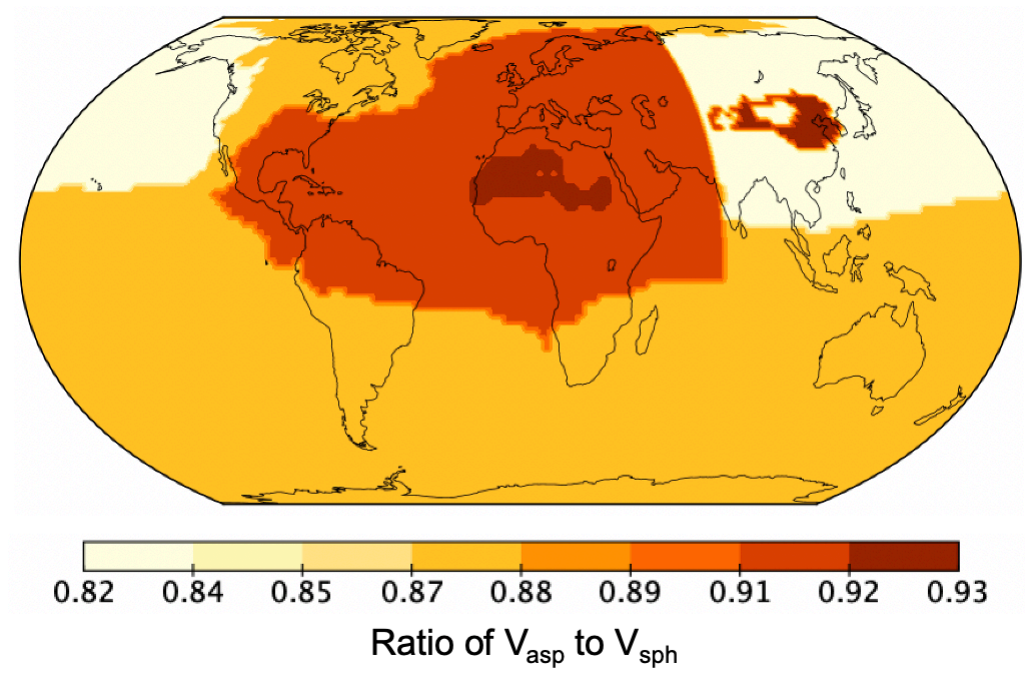


Figure S2. Comparison of the simulated dust loading (a and d), and deposition fluxes (b and d), and DOD ( $c$ and d) between the proposed new (CAM6.a) and default (CAM6.1) models on a grid-cell $(a, b$, and $c$ ) and regionally averaged basis (d). Numbers on top of panels (a-c) represent the global mean relative changes. The classic Taylor diagram compares CAM6. $\alpha$ against CAM6.1 as a reference (REF) in 21 sub-regions defined in Fig. S3. Both the standard deviation and temporal correlation (Kendall's $\mathrm{T}$ coefficient) are obtained based on the modeled monthly dust loading/deposition fluxes/DOD in each of the sub-regions with seasonal cycle removed.

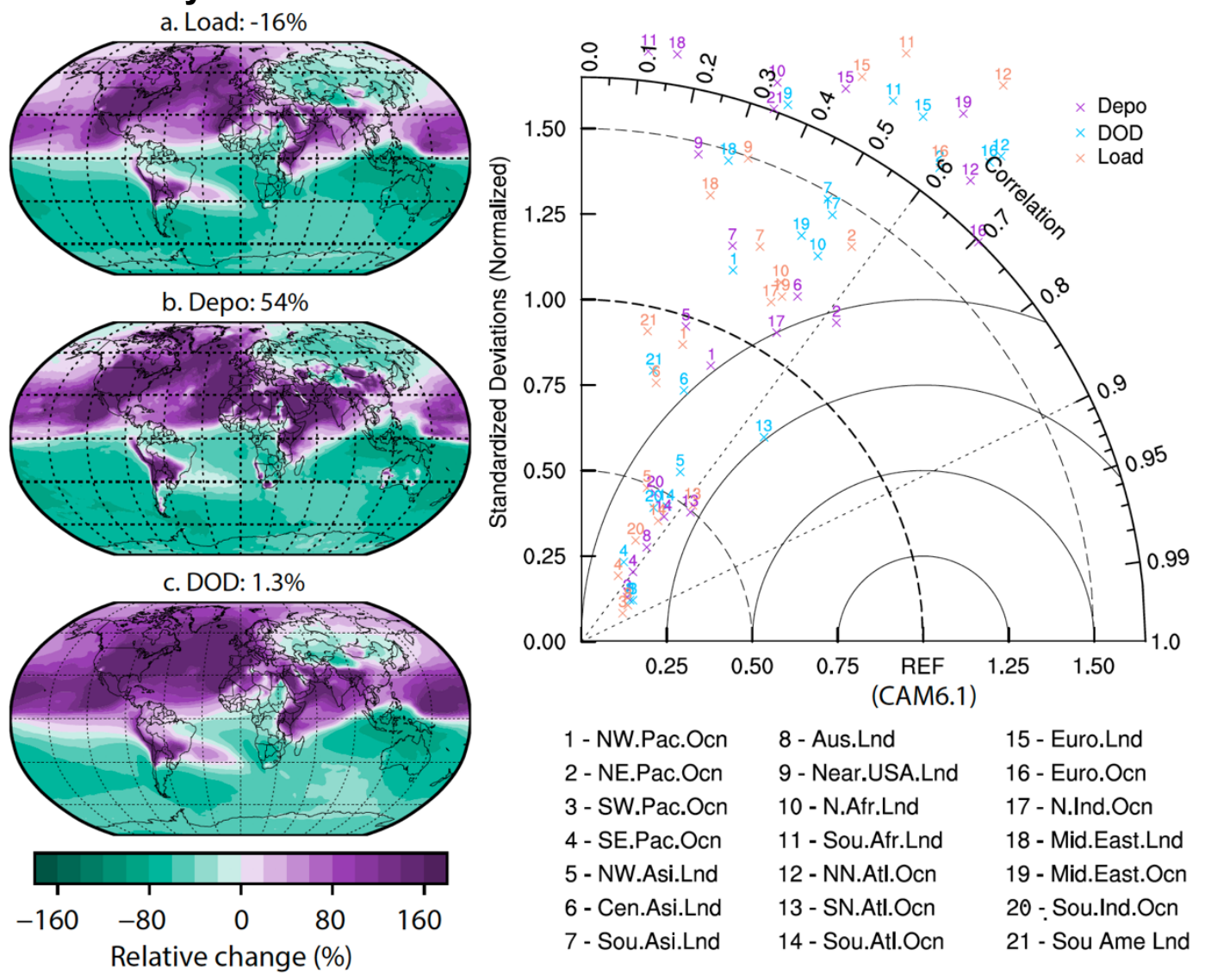


Figure S3. Comparison of modeled and observational surface concentration, deposition, and optical depth of dust.

MINE_BASE
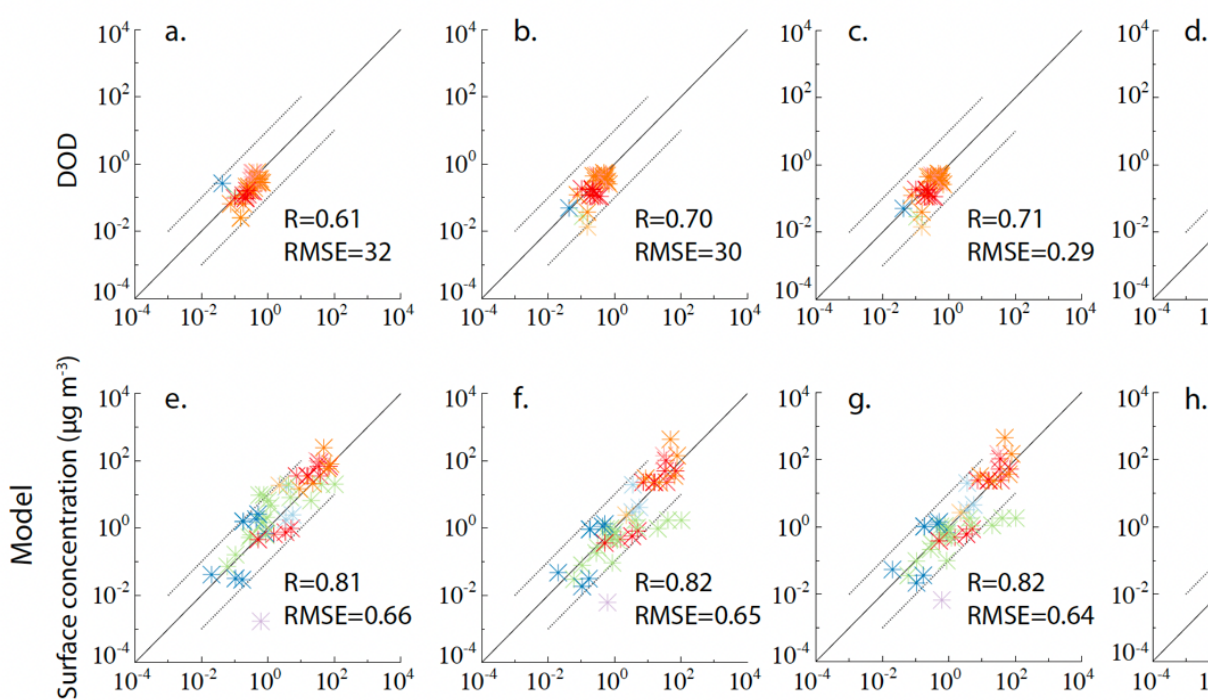

$10^{4}[\mathrm{~h}$

h.

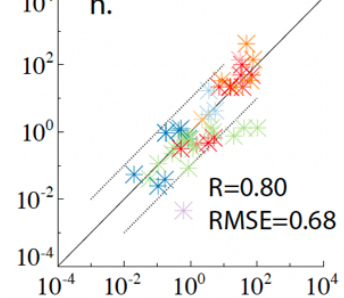

$\mathrm{R}=0.71$

RMSE=0.29 Europe

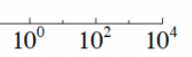

,

South Indian

North Pacific

South Pacific
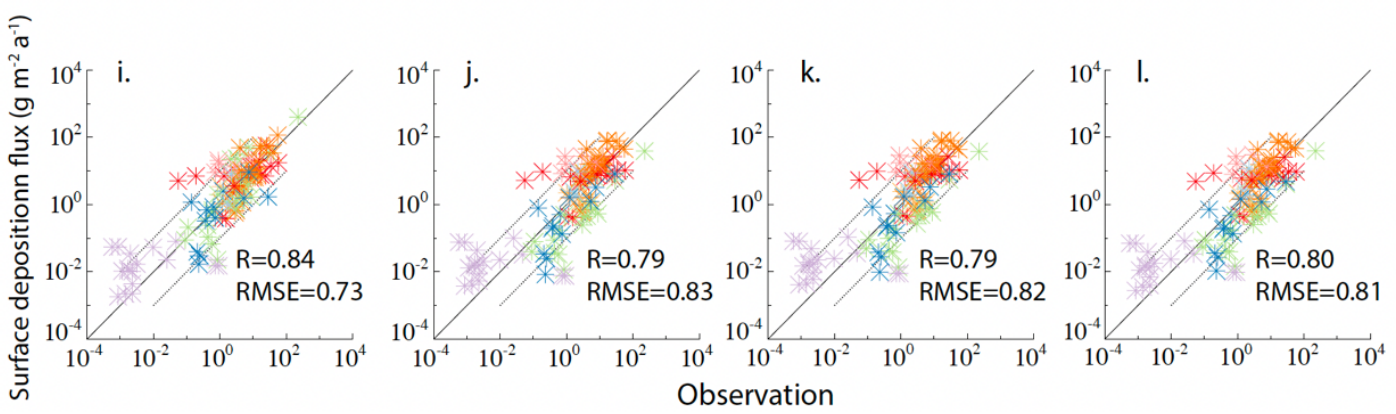
Figure S4. Dust wet deposition: percent (a) (top color bar) and ratio of model results using BRIFT to those using DEAD with the offline (b; MINE_BASE and MINE_NEW_EMIS) (bottom color bar). The number on top of each panel shows the global annual mean.

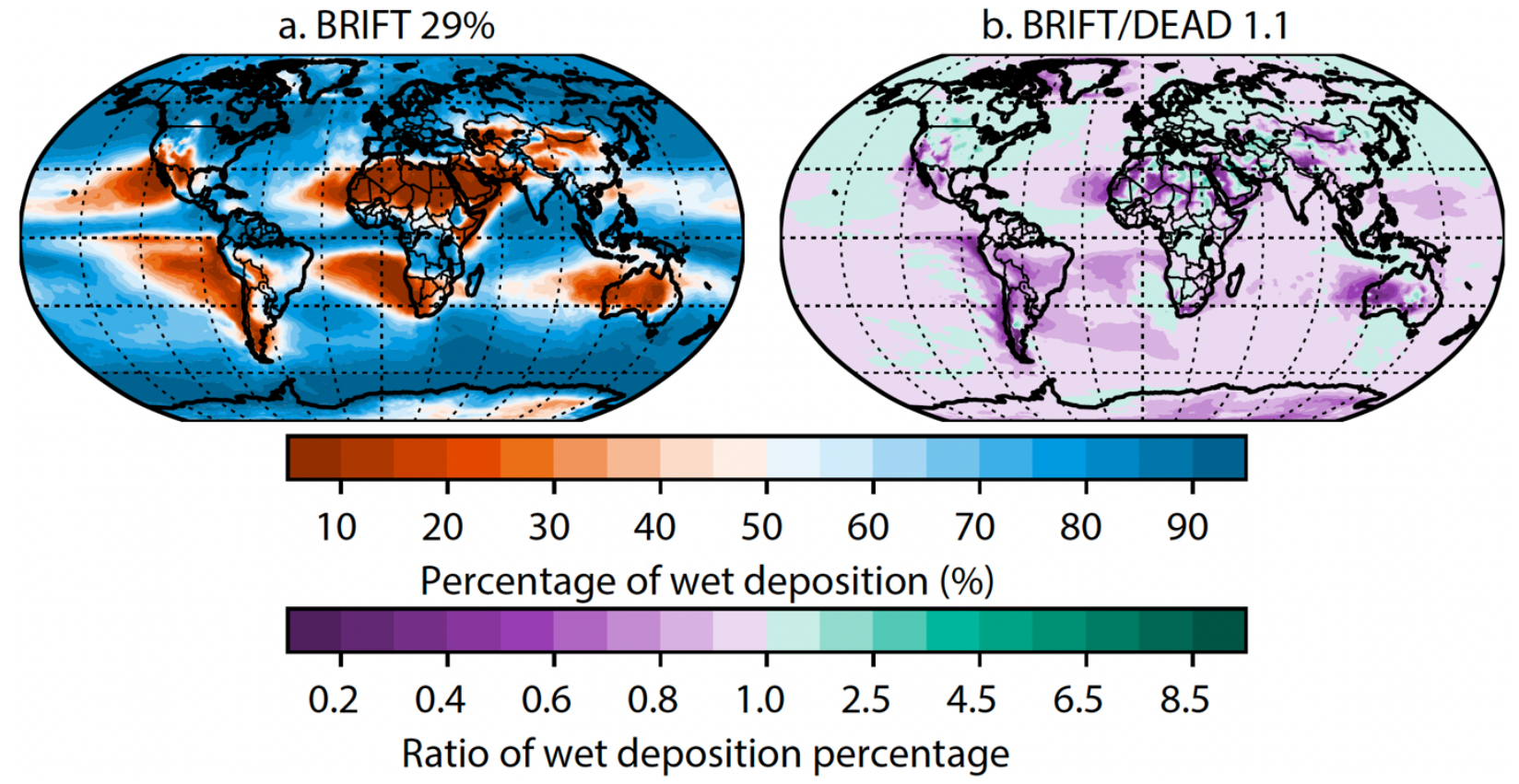


Figure S5. Seasonal cycle (x axis: 12 months) of DOD (unitless): a comparison of the simulated results (colored dots) to in situ (see site names in the figure title from a to j) measurements (grey: Obs.). Colored shading columns indicate the observed peak month: blue shows where at least one of the five cases captured the peak, and purple shows where all cases failed to capture it. Colored numbers represent the Kendell's $\mathrm{T}$ coefficient between the model and observation. Superscript star "**" indicates a statistical significance of the model-observation correlation at the $95 \%$ confidence level.

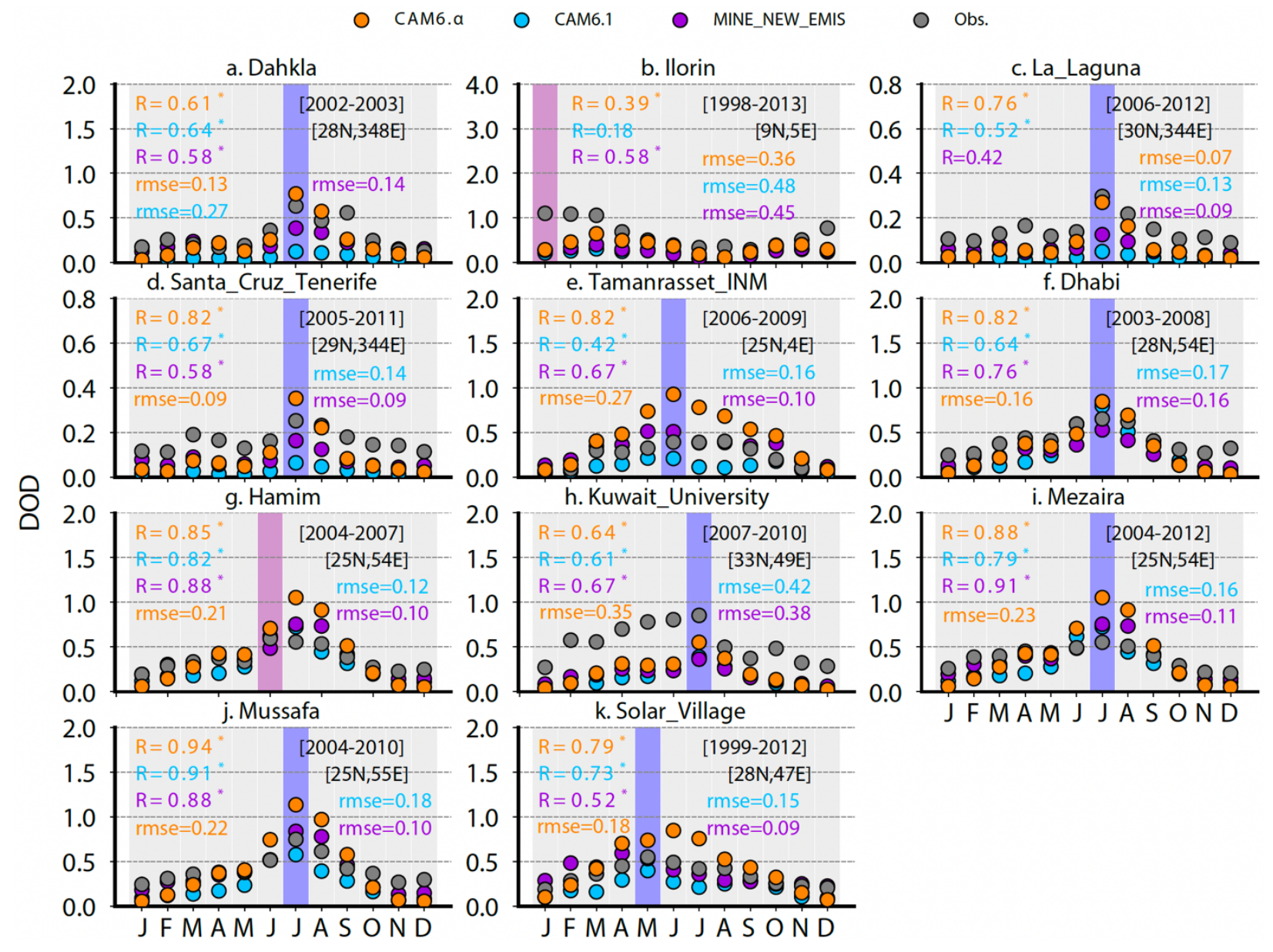


Figure S6. Comparison of seasonally (a: spring, MAM; b: summer, JJA; c, autumn, SON; d: winter, DJF) resolved regional DOD from models (y axis) to that ( $x$ axis) obtained in Ridley et al. (2016) with the region definition shown in their Fig. 1. Error bars represent the 2 standard deviations. Inlet numbers are the root mean square error (RMSE) and the spatial correlation (Kendall's $\mathrm{T}$ coefficient). Note the size distribution with $\sigma(G S D)=1.8$ represents S5, and $\sigma(G S D)=1.2$ represents $\mathbf{S 6}$ (see Table 1). Ratio of the standard deviation between the models and observations across the regional averages (model/observation) for each season and the $p$-values corresponding to the Kendall's $\mathrm{T}$ coefficient are given in Table S1.

a) MAM

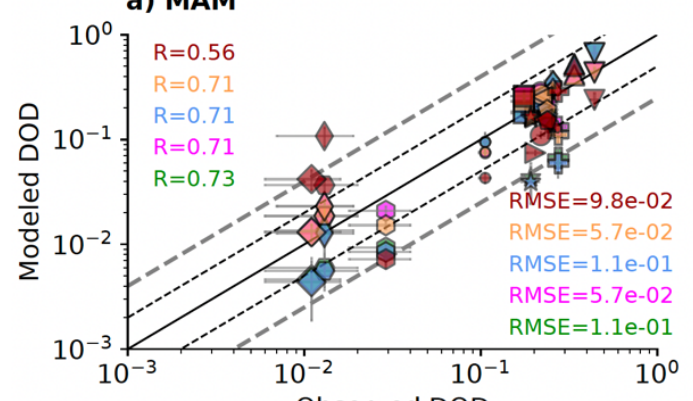

c) SON

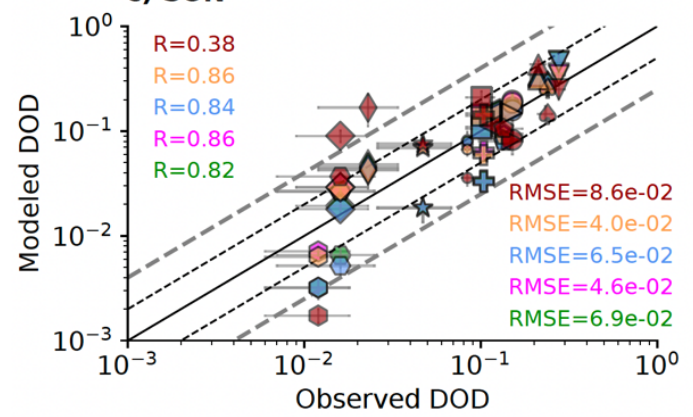

b) JJA

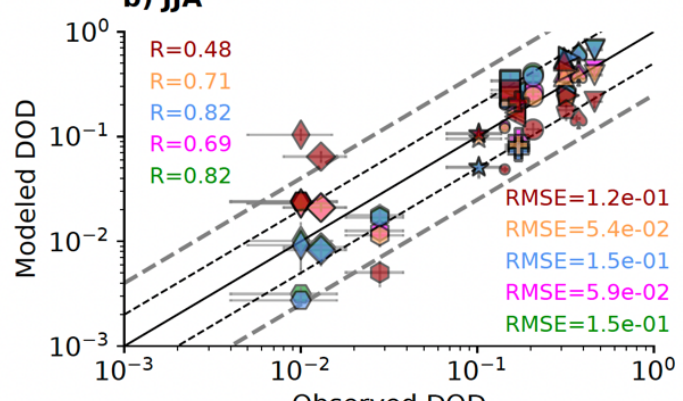

d) $\mathbf{D J F}$

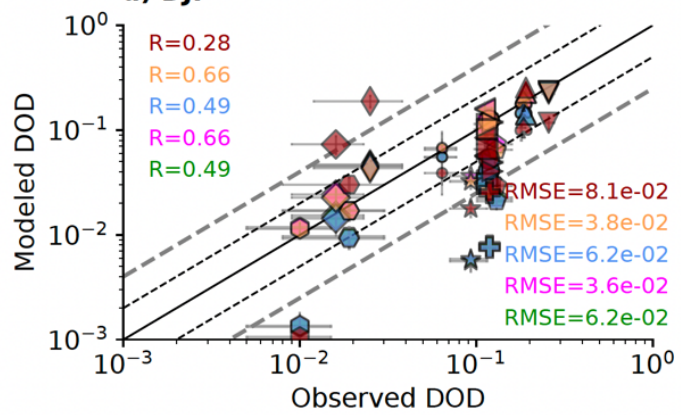

- Mid.Atlantic

\ W.Africa.Coast

O Northern.Africa

$\nabla$ Mali

$\triangle$ Bodele

$\triangleleft$ Northn.Midd.East

$\triangleright$ Southn.Midd.East

$\square$ Kyzyl.Kum

$\checkmark$ Thar

फ Taklam 
Figure $\mathrm{S} 7$. The same as Fig. S5 but for surface dust concentration (unit: $\mu \mathrm{g} \mathrm{cm}^{-3}$ ).

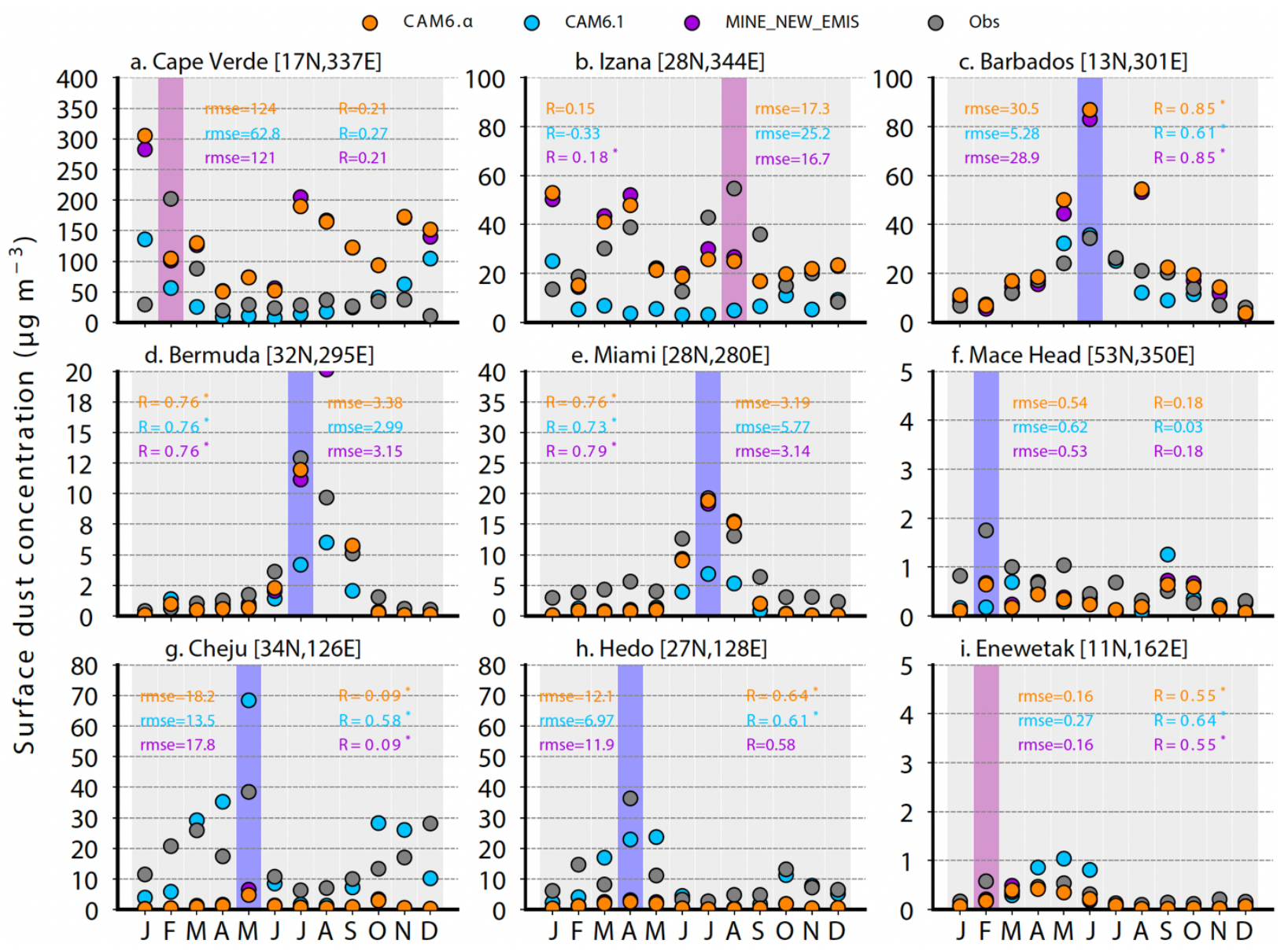


Figure S8. The same as Fig. S7 but for different sites as shown in the figure titles (a to j).

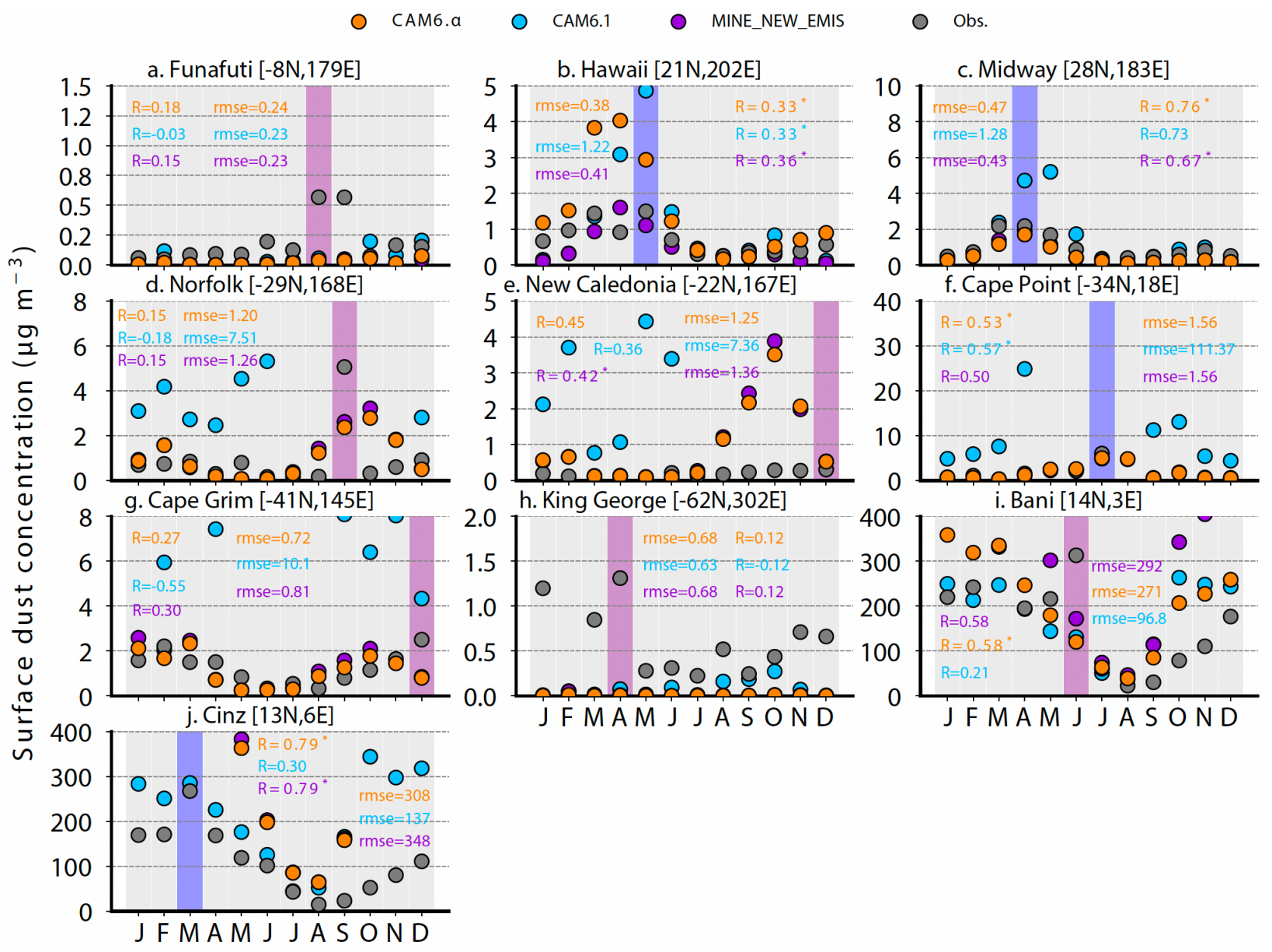


Figure S9. Modelled and observed atmospheric size-resolved dust mass in the geometric diameter range of 1-10 $\mu \mathrm{m}$ at AERONET stations. Numbers in each plot indicate the Kendall's Tau coefficient between model and observations (blue bars). The model runs here include the one using the old model with the mode size parameters from CAM6 by default (CAM6.1 in cyan) and the other one using the new model with the mode size parameters from CAM5 (CAM6. $\alpha$ in black). Both runs were using the offline dynamics.
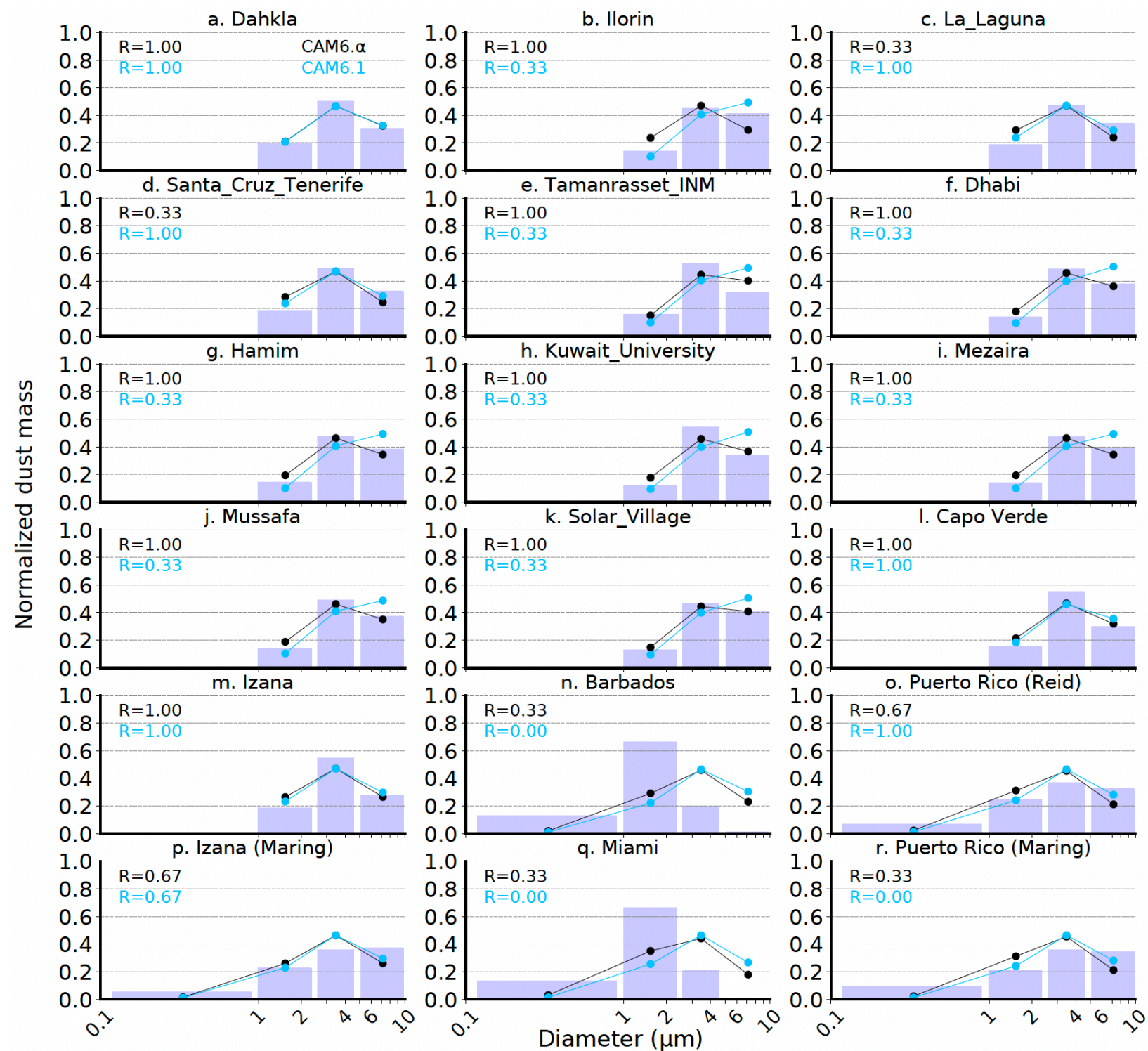
Figure S10. Normalized size distribution of dust between 0.2 and $10 \mu \mathrm{m}$ for dustspeciated CAM6.a (red lines), CAM6.1 (blue lines), and observations (dot in orange colors) at Cabo Verde and Canary Island.

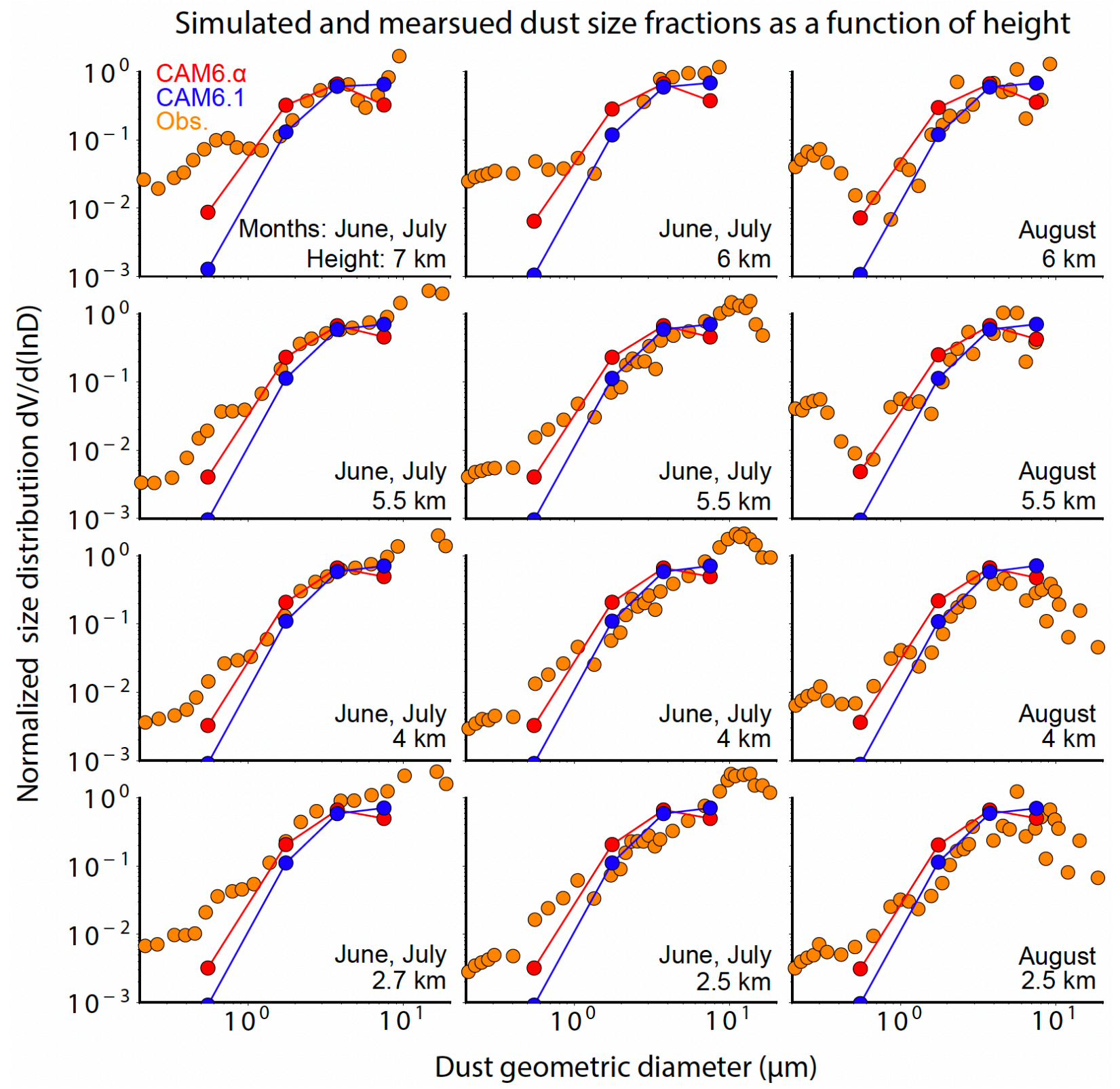


Figure S11. Dust emission flux rate $\left(\mathrm{kg} \mathrm{m}^{-2} \mathrm{~s}^{-1}\right.$; rescaled up by $\left.10^{8}\right)$ in the new model CAM6. $\alpha$ with the threshold gravimetric water content calculated following Fécan et al. (1999) using inversed clay fraction $\left(b=1 / f_{\text {clay }}\right)$. See "Calculation of the threshold gravimetric water content" in this supplement. White color indicates zero emissions.

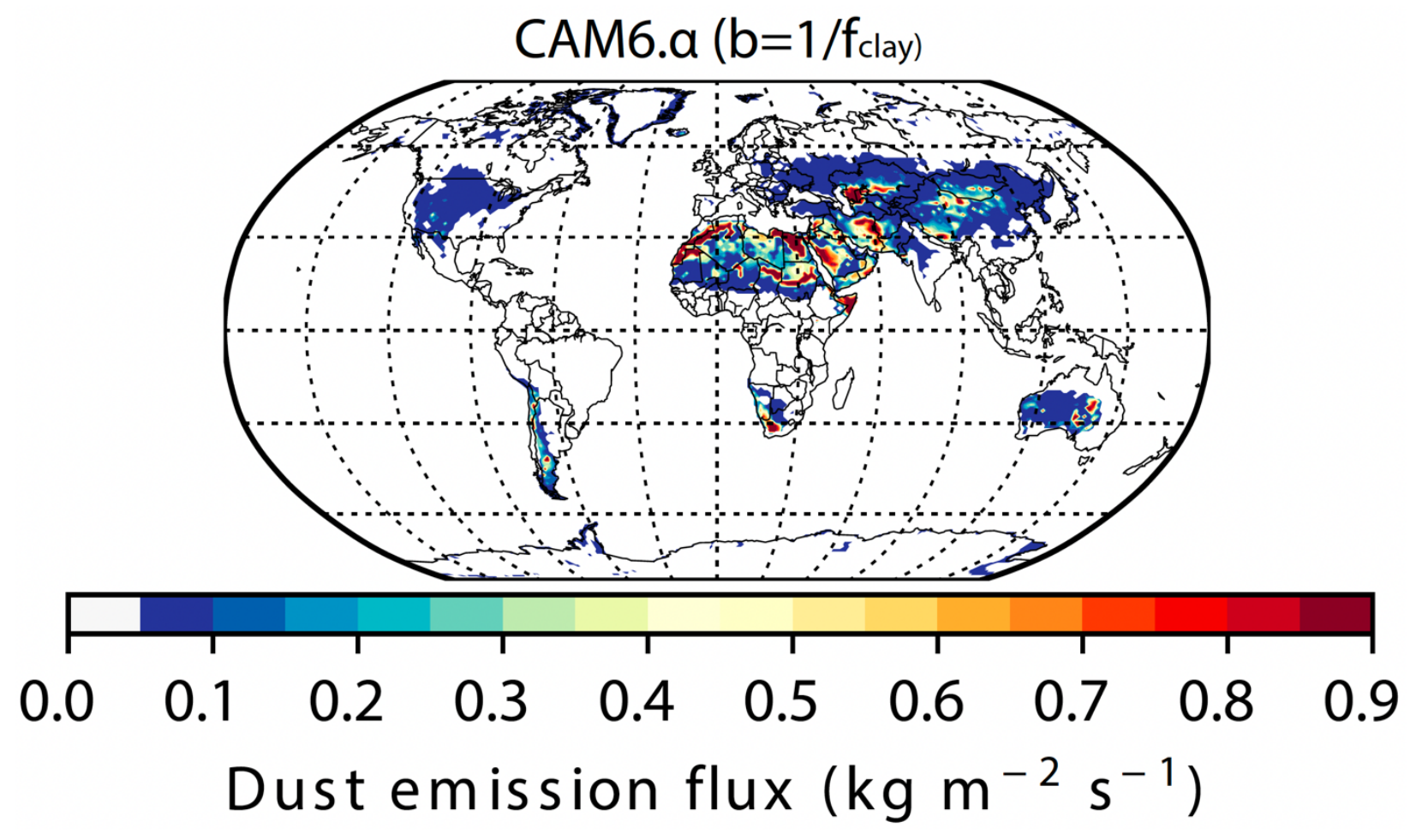


Figure S12. Sub-region division used in Fig. 1: 1. NW Pac Ocn; 2. NE Pac Ocn; 3. SW Pac Ocn; 4. SE Pac Ocn; 5. NW Asian Lnd; 6. C Asian Lnd; 7. S Asian Lnd; 8. Australia Lnd; 9. USA Lnd; 10. N Afr Lnd; 11. S Afr Lnd; 12. NN Atl Ocn; 13. SN AtI Ocn; 14. S Atl. Ocn; 15. Euro Lnd; 16. Euro Ocn; 17. N Ind Ocn; 18. Mid East Lnd; 19. Mid East Ocn; 20. S Ind Ocn; 21. S Ame Lnd

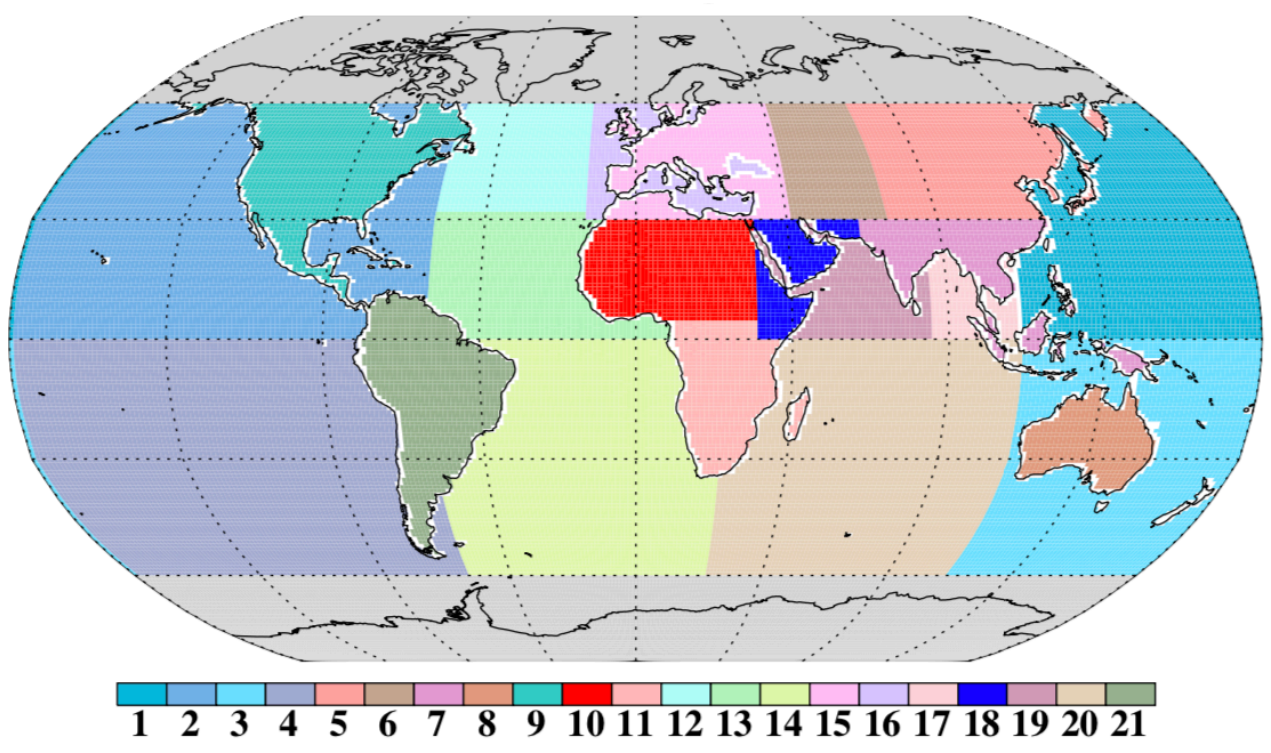


Figure S13. Change to the simulated mass fraction of hematite, smectite, illite, feldspar, kalinite, and calcite by BRIFT (MINE_NEW_EMIS) relative to DEAD (MINE_BASE).

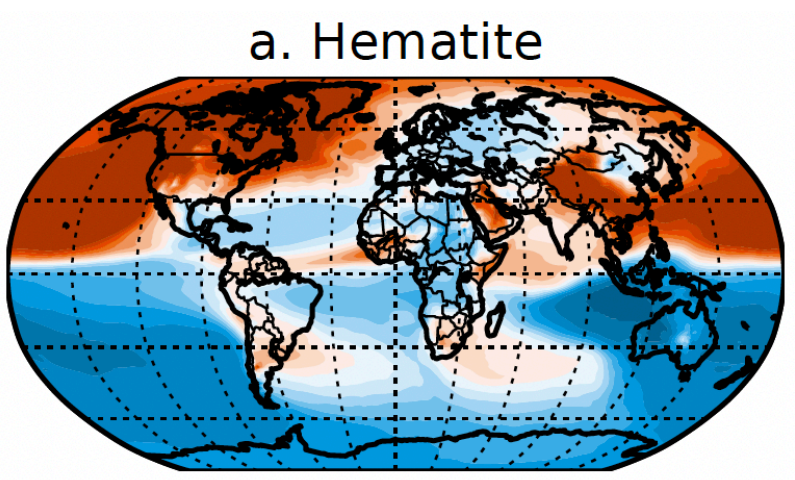

c. Illite

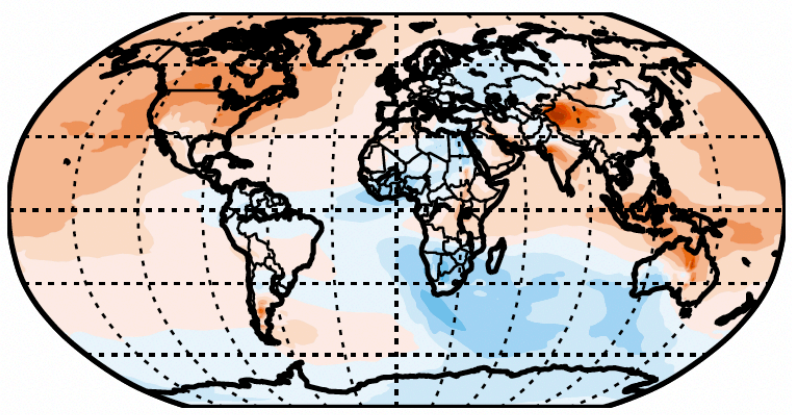

e. Kaolinite

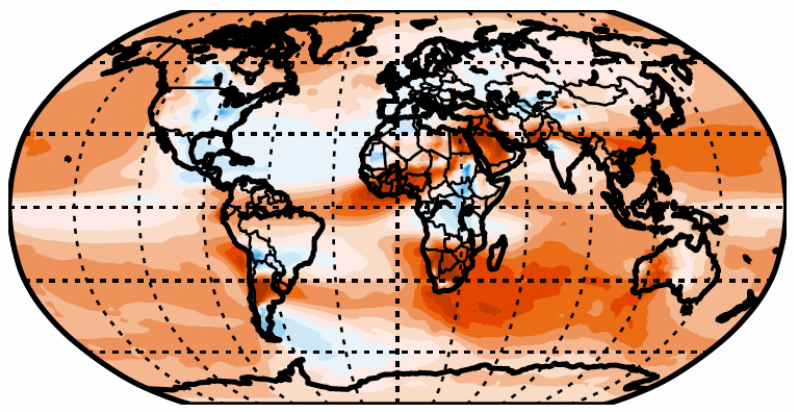

b. Smectite

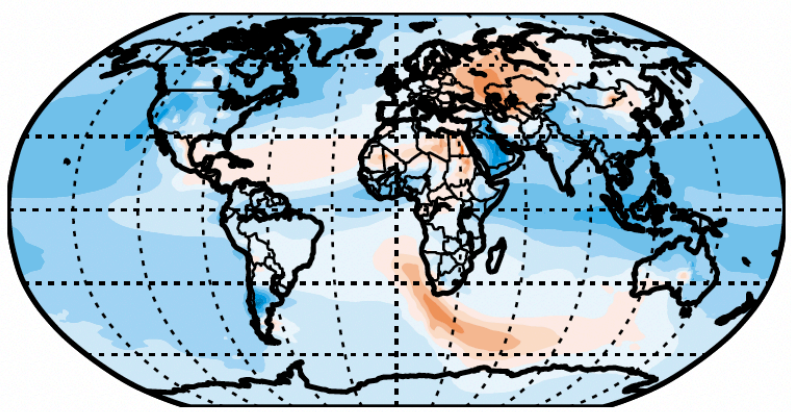

d. Feldspar

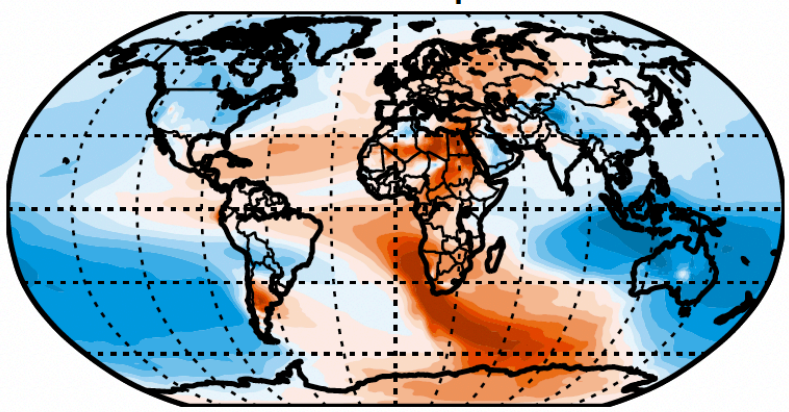

f. Calcite

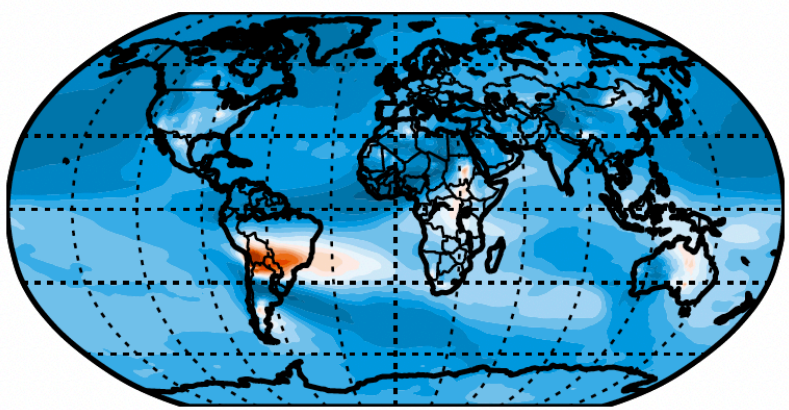

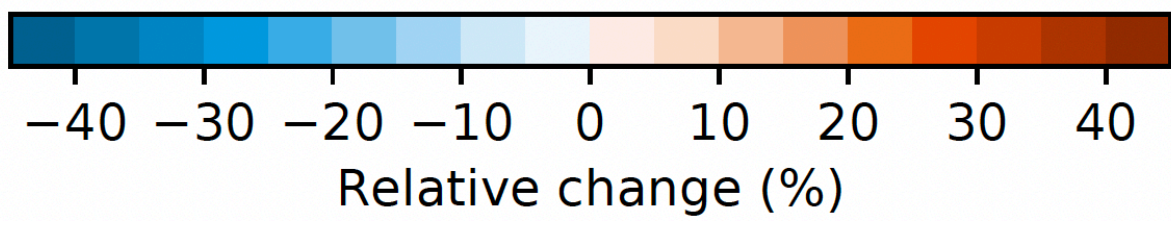


Figure S14. Modeled (all with offline dynamics and speciated dust model) surface dust dry deposition for the accumulation mode: ratio of model results using aspherical dust to those using spherical dust (a), PZ10 to Z01 (b), a combination of PZ10 and aspherical dust to that of Z01 and spherical dust (c), and BRIFT to $\operatorname{DEAD}(d)$.
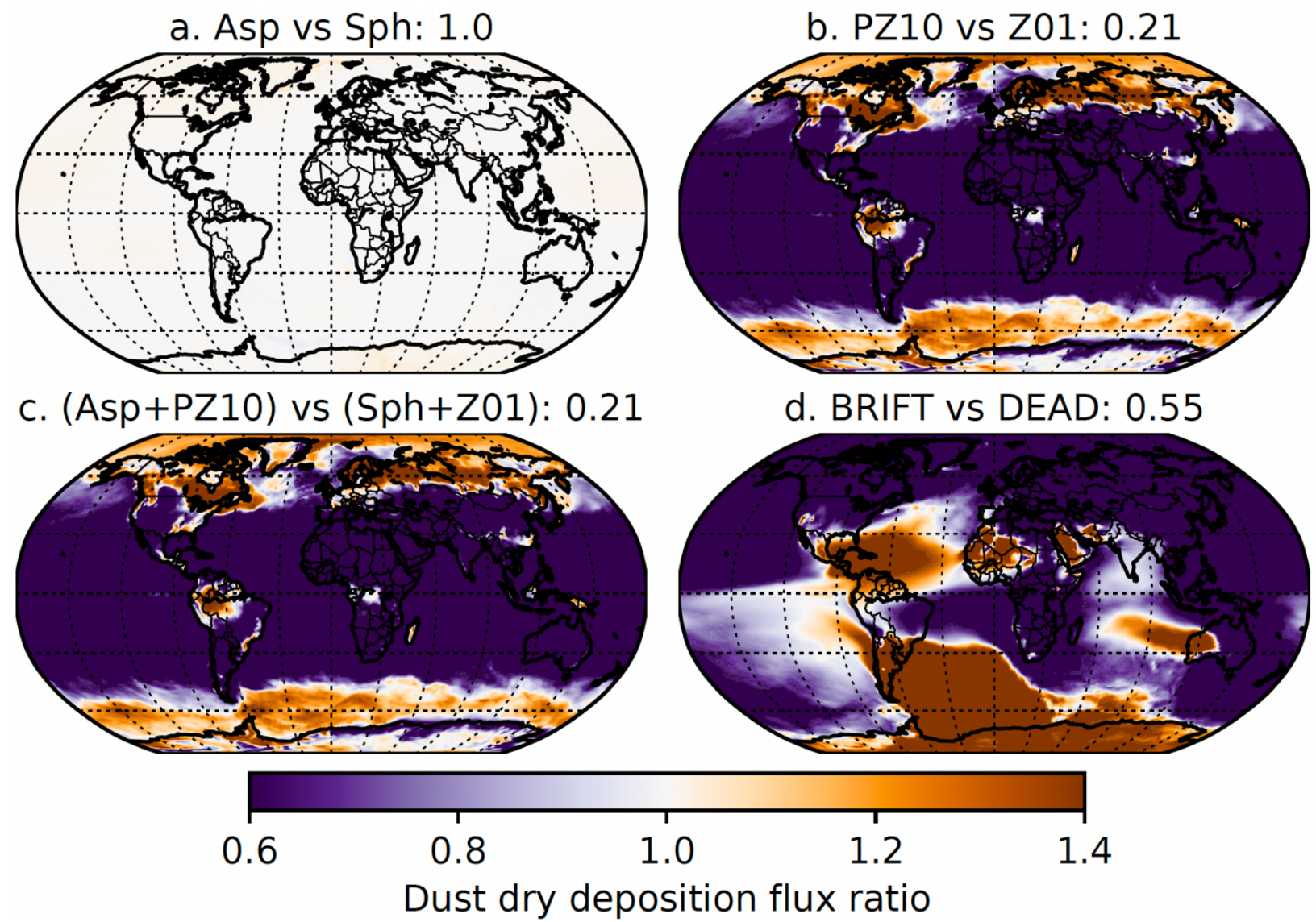
Figure S15. Modeled (all with offline dynamics and speciated dust model) dust total deposition: ratio of model results using aspherical dust to those using spherical dust (a), PZ10 to Z01 (b), a combination of PZ10 and aspherical dust to that of Z01 and spherical dust (c), and BRIFT to DEAD (d).
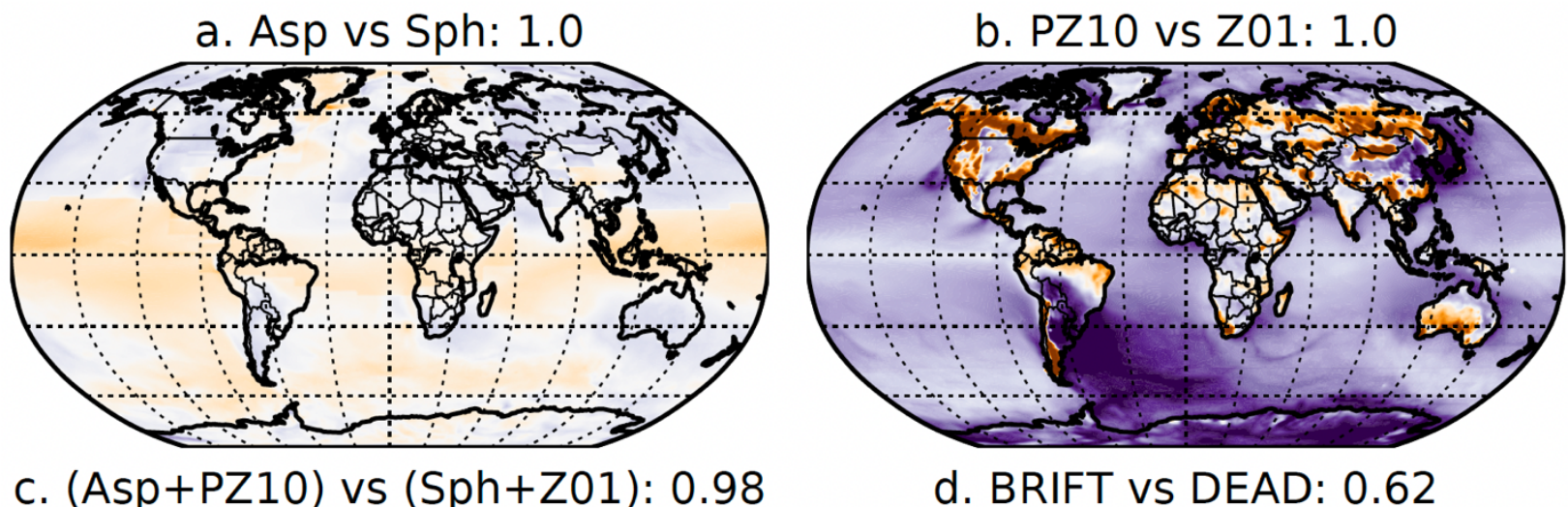

d. BRIFT VS DEAD: 0.62
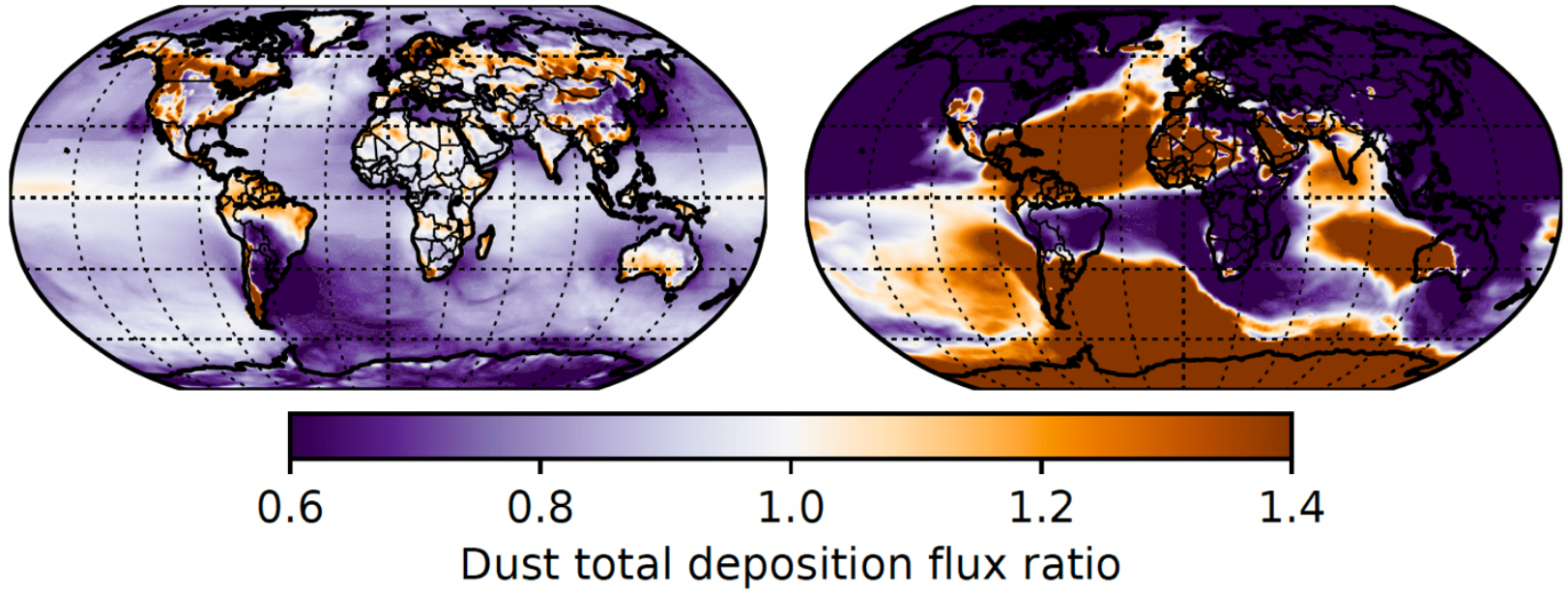
Figure S16. Same as Figs. 14 but for the wet deposition.
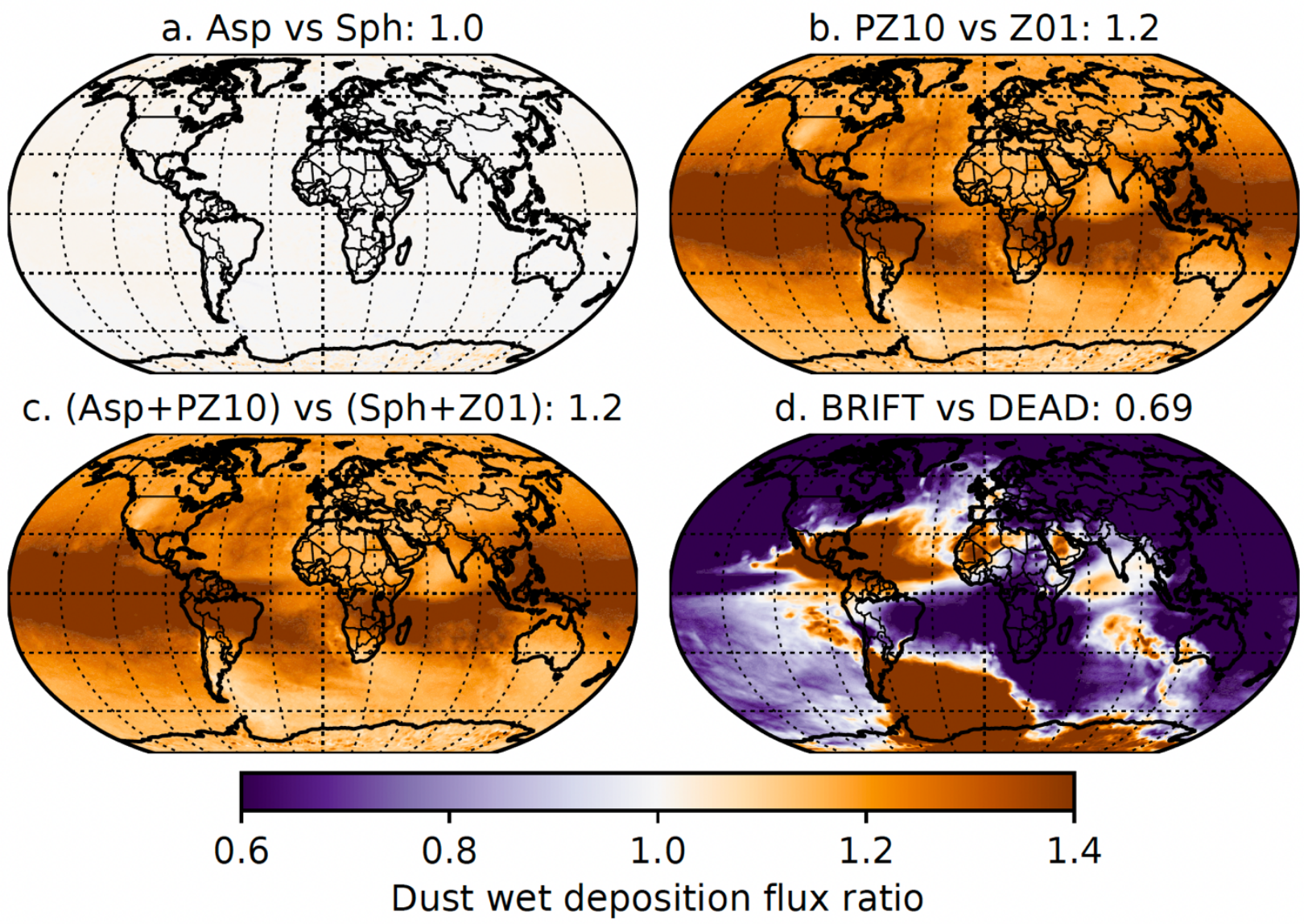
Figure S17. Dust DRE in the current climate from CAM6.1 (a); difference between CAM6.1 and CAM6. $\alpha$ (b); and difference between CAM6. $\alpha$ with the threshold gravimetric water content calculated following Fécan et al. (1999) using unity tuning factor and inversed clay fraction (CAM6.a_off) (c).
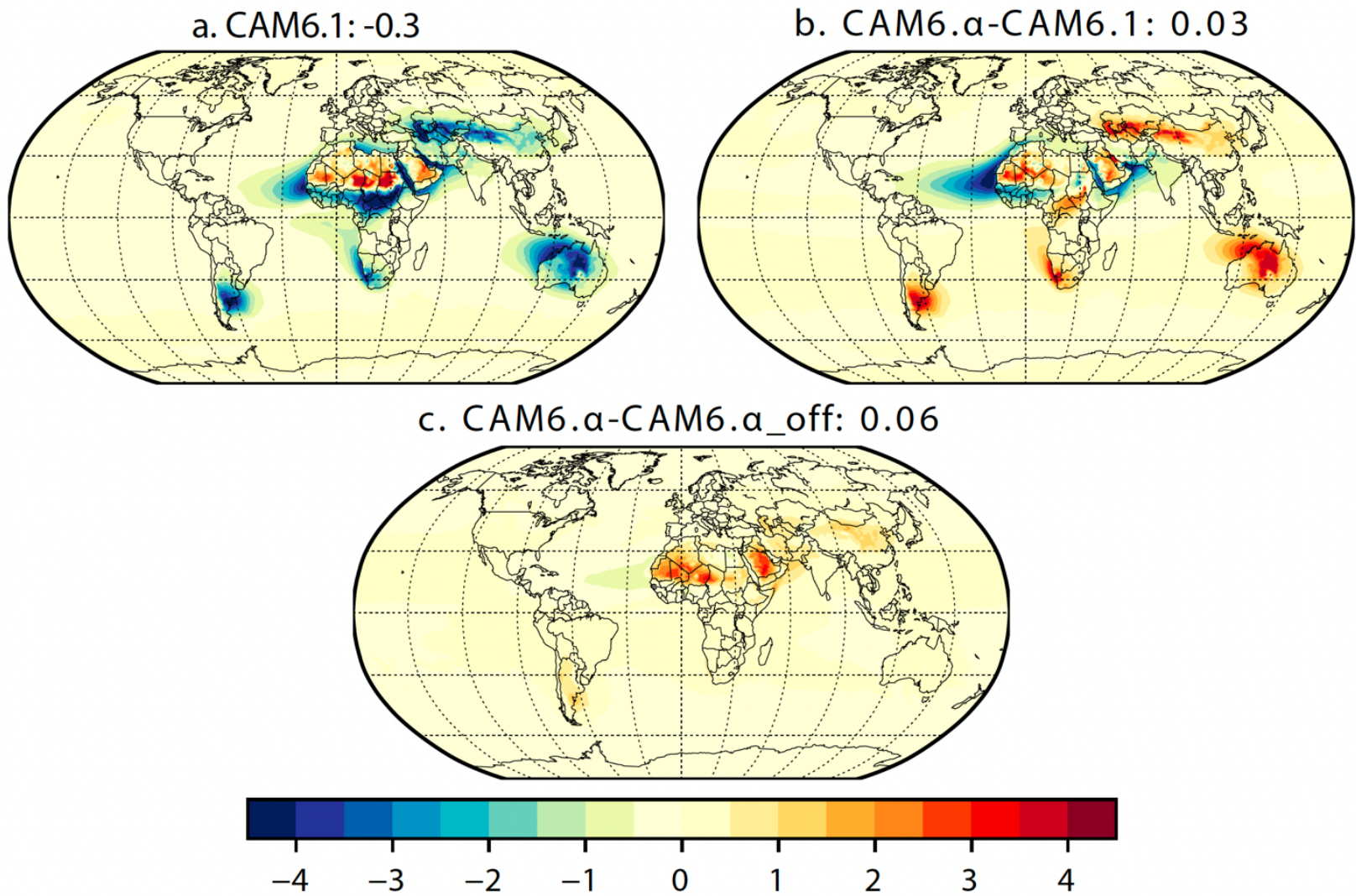

Dust net DRE and/or difference between models $\left(\mathrm{W} \mathrm{m}^{-2}\right)$ 
Figure S18. Comparison of the shortwave (SW) and longwave (LW) dust DRE in offline dynamic runs with different coarse-mode size parameters (NEW_EMIS_SIZE, NEW_EMIS, or NEW_EMIS_SIZE_WIDTH).
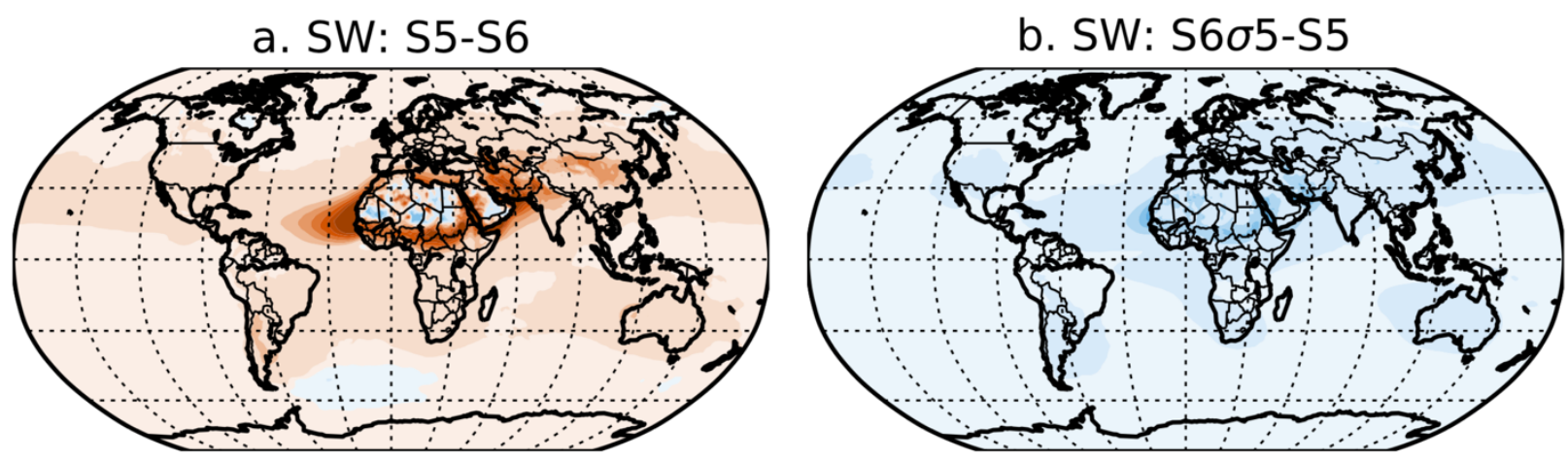

c. LW: S5-S6
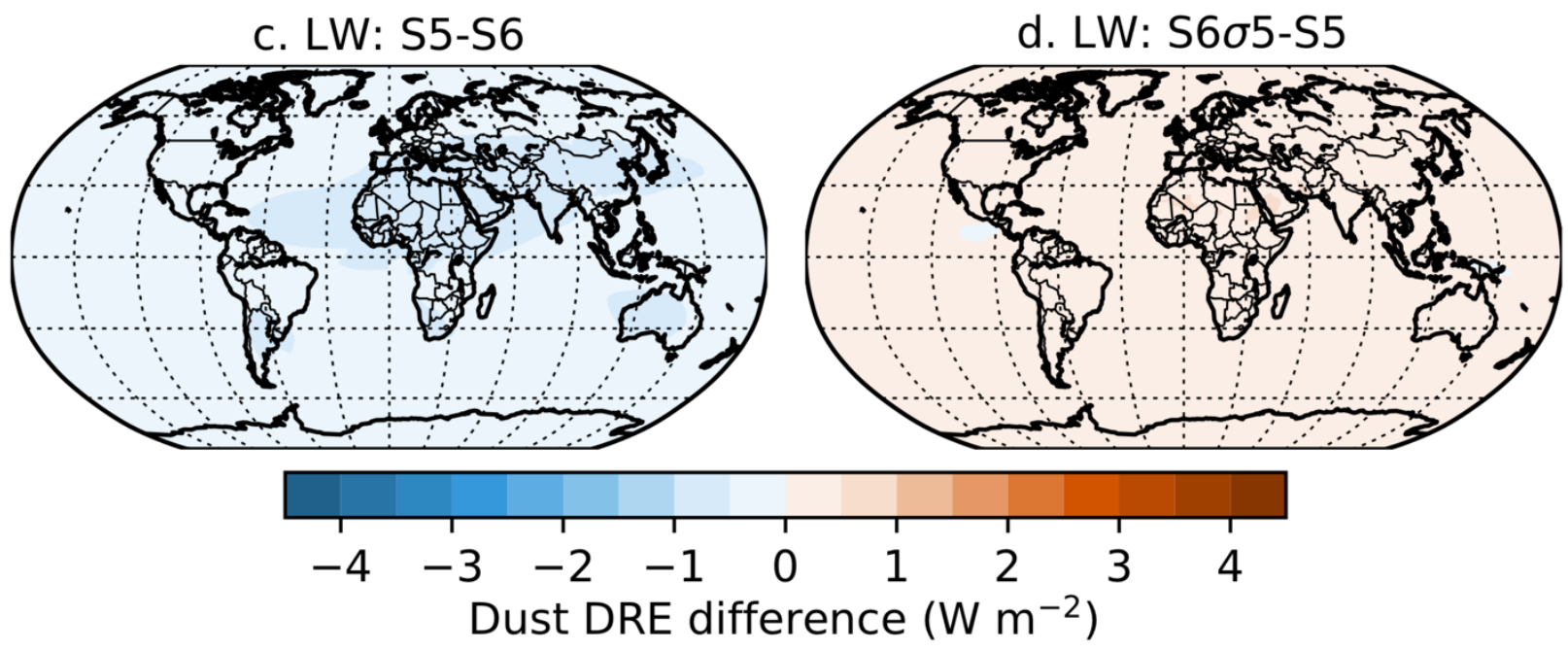


\section{Supplementary tables}

Table S1. The root mean square error (RMSE), spatial correlation (Kendall's T coefficient and the corresponding p-value given right below), and the ratio (model/observation) of SD between the modelled and "observed" DOD in Ridley et al. (2016) across the regional averages for each season.

\begin{tabular}{|c|c|c|c|}
\hline MAM & CAM6. $\alpha$ & CAM6.1 & $\begin{array}{c}\text { PZ10-Asp-K14-S5- } \\
\text { mine }\end{array}$ \\
\hline RMSE & 0.066 & 0.098 & 0.056 \\
\hline Spatial correlations & 0.65 & 0.56 & 0.69 \\
\hline P-values & 7.50E-04 & 4.10E-03 & 3.60E-04 \\
\hline $\begin{array}{c}\text { Ratios of the standard } \\
\text { deviation }\end{array}$ & 0.63 & 1.2 & 0.63 \\
\hline \multicolumn{4}{|l|}{ JJA } \\
\hline RMSEs & 0.085 & 0.12 & 0.054 \\
\hline Spatial correlations & 0.71 & 0.48 & 0.71 \\
\hline P-values & $2.50 \mathrm{E}-04$ & $1.30 \mathrm{E}-02$ & $2.50 \mathrm{E}-04$ \\
\hline $\begin{array}{c}\text { Ratios of the standard } \\
\text { deviation }\end{array}$ & 0.62 & 0.7 & 0.56 \\
\hline \multicolumn{4}{|l|}{ SON } \\
\hline RMSEs & 0.053 & 0.086 & 0.04 \\
\hline Spatial correlations & 0.78 & 0.38 & 0.86 \\
\hline P-values & 4.80E-05 & 4.70E-02 & 8.20E-06 \\
\hline $\begin{array}{c}\text { Ratios of the standard } \\
\text { deviation }\end{array}$ & 0.72 & 1.3 & 0.52 \\
\hline \multicolumn{4}{|l|}{ DJF } \\
\hline RMSEs & 0.043 & 0.081 & 0.037 \\
\hline Spatial correlations & 0.62 & 0.28 & 0.66 \\
\hline P-values & $8.40 \mathrm{E}-04$ & $1.70 \mathrm{E}-01$ & 3.30E-04 \\
\hline $\begin{array}{c}\text { Ratios of the standard } \\
\text { deviation }\end{array}$ & 0.64 & 0.83 & 0.67 \\
\hline
\end{tabular}




\section{References}

Adebiyi, A., Kok, J., Wang, Y., Ito, A., Ridley, D., Nabat, P. and Zhao, C.: Dust Constraints from joint Observational-Modelling-experiMental analysis (DustCOMM): Comparison with measurements and model simulations, Atmos. Chem. Phys., 829-863, doi:10.5194/acp-2019-484, 2020.

Albani, S., Mahowald, N. M., Perry, A. T., Scanza, R. A., Zender, C. S., Heavens, N. G., Maggi, V., Kok, J. F. and Otto-Bliesner, B. L.: Improved dust representation in the Community Atmosphere Model, 2014.

Bagheri, G. and Bonadonna, C.: On the drag of freely falling non-spherical particles, Powder Technol., 301, 526-544, doi:10.1016/j.powtec.2016.06.015, 2016.

Dubovik, O., Smirnov, A., Holben, B. N., King, M. D., Kaufman, Y. J., ECK, T. F. and Slutsker, I.: Accuracy assessments of aerosol optical properties retrieved from Aerososl Robotic Network (AERONET) Sun and sky radiance measurments, J. Geophys. Res., 105(D8), 9791-9806, 2000.

FAO/IIASA/ISRIC/ISSCAS/JRC: Harmonized World Soil Database (version 1.2), FAO, Rome, Italy and IIASA, Laxenburg, Austria., 2012.

Fecan, F., Marticorena, B. and Bergametti, G.: Parameterization of the increase of the aeolian erosion threshold wind friction velocity due to soil moisture for arid and semiarid areas, Ann. Geophys. Hydrospheres Sp. Sci., 17, 149-157, 1999.

Ginoux, P., Chin, M., Tegen, I., Goddard, T. and In-, G.: Sources and distributions of dust aerosols simulated with the GOCART model, J. Geophys. Res., 106, 2025520273, 2001.

Huang, Y., Kok, J. F., Kandler, K., Lindqvist, H., Nousiainen, T., Sakai, T., Adebiyi, A. and Jokinen, O.: Climate Models and Remote Sensing Retrievals Neglect Substantial Desert Dust Asphericity, Geophys. Res. Lett., 47(6), 1-11, doi:10.1029/2019GL086592, 2020.

Kim, D., Chin, M., Yu, H., Diehl, T., Tan, Q., Kahn, R. A., Tsigaridis, K., Bauer, S. E., Takemura, T., Pozzoli, L., Bellouin, N., Schulz, M., Peyridieu, S., Chédin, A. and Koff, B.: Sources, sinks, and transatlantic transport of North African dust aerosol: A multimodel analysis and comparison with remote sensing data, J. Geophys. Res. Atmos., 119, 6259-6277, doi:10.1002/2013JD021099, 2014.

Kok, J. F., Albani, S., Mahowald, N. M. and Ward, D. S.: An improved dust emission model - Part 2: Evaluation in the Community Earth System Model, with implications for the use of dust source functions, Atmos. Chem. Phys., 14(23), doi:10.5194/acp-1413043-2014, 2014.

Kok, J. F., Adebiyi, A. A., Albani, S., Balkanski, Y., Checa-Garcia, R., Chin, M., Colarco, P. R., Hamilton, D. S., Huang, Y., Ito, A., Klose, M., Li, L., Mahowald, N. M., Miller, R. L., Obiso, V., Pérez García-Pando, C., Rocha-Lima, A. and Wan, J. S.: Contribution of the world's main dust source regions to the global cycle of desert dust, Atmos. Chem. Phys., 21(10), 8169-8193, doi:10.5194/acp-21-8169-2021, 2021.

Lawrence, C. R. and Neff, J.: The contemporary physical and chemical flux of Aeolian dust: a synthesis of direct measurements of dust deposition, Chem. Geol., 257, 46-63, doi:https://doi.org/10.1016/j.chemgeo.2009.02.005, 2009.

Luo, T., Wang, Z., Zhang, D., Liu, X., Wang, Y. and Yuan, R.: Global dust distribution from improved thin dust layer detection using A-train satellite lidar observations, 
Geophys. Res. Lett., 42(2), 620-628, doi:10.1002/2014GL062111, 2015a.

Luo, T., Wang, Z., Ferrare, R. A., Hostetler, C. A., Yuan, R. and Zhang, D.: Vertically resolved separation of dust and other aerosol types by a new lidar depolarization method, Opt. Express, 23(11), 14095, doi:10.1364/oe.23.014095, 2015b.

Mahowald, N., Albani, S., Kok, J. F., Engelstaeder, S., Scanza, R., Ward, D. S. and Flanner, M. G.: The size distribution of desert dust aerosols and its impact on the Earth system, Aeolian Res., 15, doi:10.1016/j.aeolia.2013.09.002, 2014.

Mahowald, N. M., Engelstaedter, S., Luo, C., Sealy, A., Artaxo, P., Benitez-Nelson, C., Bonnet, S., Chen, Y., Chuang, P. Y., Cohen, D. D., Dulac, F., Herut, B., Johansen, A. M., Kubilay, N., Losno, R., Maenhaut, W., Paytan, A., Prospero, J. M., Shank, L. M. and Siefert, R. L.: Atmospheric iron deposition: Global distribution, variability, and human perturbations, Ann. Rev. Mar. Sci., 1, doi:10.1146/annurev.marine.010908.163727, 2009.

Mallios, S. A., Drakaki, E. and Amiridis, V.: Effects of dust particle sphericity and orientation on their gravitational settling in the earth's atmosphere, J. Aerosol Sci., 150(April), 1-21, doi:10.1016/j.jaerosci.2020.105634, 2020.

McConnell, C. L., Highwood, E. J., Coe, H., Formenti, P., Anderson, B., Osborne, S., Nava, S., Desboeufs, K., Chen, G. and Harrison, M. A. J.: Seasonal variations of the physical and optical characteristics of saharan dust: Results from the dust outflow and deposition to the ocean (DODO) experiment, J. Geophys. Res., 113, 1-19, doi:10.1029/2007JD009606, 2008.

Otto, S., De Reus, M., Trautmann, T., Thomas, A., Wendisch, M. and Borrmann, S.: Atmospheric radiative effects of an in situ measured Saharan dust plume and the role of large particles, Atmos. Chem. Phys., 7(18), 4887-4903, doi:10.5194/acp-7-4887-2007, 2007.

Platt, C. M. R., Abshire, N. L. and McNice, G. T.: Some Microphysical Properties of an Ice Cloud from Lidar Observation of Horizontally Oriented Crystals, J. Appl. Meteorol. Climatol., 17, 1220-1224, doi:https://doi.org/10.1175/15200450(1978)017<1220:SMPOAI>2.0.CO;2, 1978.

Pu, B., Ginoux, P., Guo, H., Christina Hsu, N., Kimball, J., Marticorena, B., Malyshev, S., Naik, V., O’Neill, N. T., Pérez García-Pando, C., Paireau, J., Prospero, J. M., Shevliakova, E. and Zhao, M.: Retrieving the global distribution of the threshold of wind erosion from satellite data and implementing it into the Geophysical Fluid Dynamics Laboratory land-atmosphere model (GFDL AM4.0/LM4.0), Atmos. Chem. Phys., 20(1), 55-81, doi:10.5194/acp-20-55-2020, 2020.

Ridley, D., Heald, C., Kok, J. and Zhao, C.: An observationally-constrained estimate of global dust aerosol optical depth, Atmos. Chem. Phys., doi: 10.5194/acp--2016--385, 2016.

Ryder, C. L., Highwood, E. J., Rosenberg, P. D., Trembath, J., Brooke, J. K., Bart, M., Dean, A., Crosier, J., Dorsey, J., Brindley, H., Banks, J., Marsham, J. H., McQuaid, J. B., Sodemann, H. and Washington, R.: Optical properties of Saharan dust aerosol and contribution from the coarse mode as measured during the Fennec 2011 aircraft campaign, Atmos. Chem. Phys., 13(1), 303-325, doi:10.5194/acp-13-303-2013, 2013. Ryder, C. L., Marenco, F., Brooke, J. K., Estelles, V., Cotton, R., Formenti, P., McQuaid, J. B., Price, H. C., Liu, D., Ausset, P., Rosenberg, P. D., Taylor, J. W., Choularton, T., Bower, K., Coe, H., Gallagher, M., Crosier, J., Lloyd, G., Highwood, E. J. and Murray, B. 
J.: Coarse-mode mineral dust size distributions, composition and optical properties from AER-D aircraft measurements over the tropical eastern Atlantic, Atmos. Chem. Phys., 18(23), 17225-17257, doi:10.5194/acp-18-17225-2018, 2018.

Tegen, I., Harrison, S. P., Kohfeld, K., Prentice, C., Coe, M. and Heimann, M.: The impact of vegetation and preferential source areas on global dust aerosol: Results from a model study, J. Geophys. Res., 107(D21), 4576, doi:https://doi.org/10.1029/2001JD000963, 2002.

Tobo, Y., Zhang, D., Matsuki, A. and Iwasaka, Y.: Asian dust particles converted into aqueous droplets under remote marine atmospheric conditions, Proc. Natl. Acad. Sci. U. S. A., 107(42), 17905-17910, doi:10.1073/pnas.1008235107, 2010.

Yang, W., Marshak, A., Kostinski, A. B. and Várnai, T.: Shape-induced gravitational sorting of Saharan dust during transatlantic voyage: Evidence from CALIOP lidar depolarization measurements, Geophys. Res. Lett., 40(12), 3281-3286, doi:10.1002/grl.50603, 2013.

Zuidema, P., Alvarez, C., Kramer, S. J., Custals, L., Izaguirre, M., Sealy, P., Prospero, J. M. and Blades, E.: Is summer African dust arriving earlier to Barbados?, Bull. Am. Meteorol. Soc., 100(10), 1981-1986, doi:10.1175/BAMS-D-18-0083.1, 2019. 